\title{
Taxic Responses in Phormidium uncinatum
}

\author{
By GEORGI V. MURVANIDZE, VLADIMIR L. GABAI AND \\ ALEKSEI N. GLAGOLEV* \\ A. N. Belozersky Laboratory of Molecular Biology and Bioorganic Chemistry, Moscow State \\ University, Moscow 117234, U.S.S.R.
}

(Received 1 July 1981; revised 14 September 1981)

\begin{abstract}
Cyanobacteria respond to a decrease in light intensity by reversing their direction of gliding. The sensitivity of the phototactic response in Phormidium uncinatum increased two- to threefold under anaerobic conditions. Light-dependent changes in the membrane potential $(\Delta \psi)$, as measured by tetraphenylphosphonium distribution, were also found to be larger in anaerobic conditions, suggesting that the photophobic response is governed by sensing of the protonmotive force $\left(\Delta \bar{\mu}_{\mathrm{H}^{+}}\right)$. The uncoupler carbonyl cyanide $m$-chlorophenylhydrazone (CCCP), when added to P. uncinatum trichomes, also evoked a phobic response in a spatial gradient assay. The extent of repulsion by different concentrations of CCCP correlated with its ability to decrease $\Delta \psi$. A viscous environment, exudates of an old culture, or high concentrations of $\mathrm{Ca}^{2+}$ (plus the ionophore A23187) caused oscillatory reversals and a partial asynchronization of cells within a trichome. EGTA or CCCP in high concentrations restored synchronization. Ethionine inhibited reversals and the addition of $10^{-6} \mathrm{M}^{-\mathrm{Ca}^{2+}}$ (plus A23187) restored photophobic sensitivity. A depolarizing electrical potential spread from the leading end (the 'head') of the trichomes following a decrease in light intensity. It is suggested that sensing of $\Delta \bar{\mu}_{\mathrm{H}}$. or chemoeffectors leads to a methylation-requiring step followed by a taxic signal in the form of simultaneous changes in $\Delta \psi$ and $\mathrm{Ca}^{2+}$ concentration.
\end{abstract}

\section{INTRODUCTION}

In bacterial taxis, information is processed through several steps: reception, summation, adaptation, signal transmission to flagella and, finally, reversal of flagellar motors. By modulating the frequency of flagellar reversals, bacteria respond to gradients of attractants and repellents (Larsen et al., 1974).

Cyanobacteria are especially suitable for studying the mechanism of integrating sensory information, since the trichomes are composed of many hundreds of cells, combined in an electrically unified structure (Glagolev et al., 1980). Phototaxis in cyanobacteria has been extensively studied (Nultsch, 1962; Nultsch \& Häder, 1979, Häder, 1977; 1978 a, b, 1979). Apart from the sensing of specific chemoeffectors, bacteria are able to sense protonmotive force $\left(\Delta \bar{\mu}_{\mathrm{H}}\right)$ (Miller \& Koshland, 1977). It has been suggested that phototaxis is a particular case of $\Delta \bar{\mu}_{\mathrm{H}^{+}}$sensing governed by a special receptor, named a protometer (Glagolev, 1978 , 1980). Changes in $\Delta \bar{\mu}_{\mathrm{H}}$ occurring in individual cells, due to variations in light intensity or other factors, may be integrated throughout the electrically unified trichome. After registering a change in $\Delta \bar{\mu}_{\mathrm{H}}$, the protometer may send the information to the taxis machinery which then generates a taxic signal. If this signal were of an electrical nature (as suggested by Häder,

Abbreviations: CCCP, carbonyl cyanide $m$-chlorophenylhydrazone: FCCP. trifluoromethoxycarbonyl cyanide phenylhydrazone; TPMP', triphenylmethylphosphonium; TPP', tetraphenylphosphonium: TTFB, tri fluorotetrachlorobenzimidazole: $\Delta \bar{\mu}_{\mathrm{H}^{+}}$, transmembrane electrochemical potential of $\mathbf{H}^{+}$ions; $\Delta \psi$, transmembrane electrical potential difference; MCP. methyl-accepting chemotaxis protein. 
$1978 a, b)$, the cells would be able to react uniformly by reversing. Although cyanobacteria lack flagella, they possess fibrils underlying the outer membrane (Halfen \& Castenholz, 1971), whose rotation results in gliding. The energy source for motility in cyanobacteria, as in eubacteria, is $\Delta \bar{\mu}_{\mathrm{H}^{+}}$(Glagoleva et al., 1980). By analogy with flagella, the rotation of cyanobacterial fibrils may be reversed on receiving a taxic signal.

In Bacillus subtilis, $\mathrm{Ca}^{2+}$ ions have been found to be necessary for flagellar reversals (Ordal, 1977) and we have recently found that $\mathrm{Ca}^{2+}$ plays a similar role in the reversals of Phormidium uncinatum trichomes (Murvanidze \& Glagolev, 1981).

The purpose of the present study was to investigate the interplay of phototaxis, the signal that is transmitted (probably $\Delta \psi$ ) and $\mathrm{Ca}^{2+}$ in the behaviour of P. uncinatum.

\section{METHODS}

Organism and growth conditions. Phormidium uncinatum, isolated from Lake Baikal, was used throughout (Glagoleva et al., 1980). P. uncinatum trichomes are $4 \mu \mathrm{m}$ wide and 50-3000 $\mu \mathrm{m}$ long; they glide on the surface of $2 \%(\mathrm{w} / \mathrm{v})$ agar with a speed of $3 \mu \mathrm{m} \mathrm{s}^{-1}$. Phototactically active $72 \mathrm{~h}$ cultures were used. Trichomes were cultivated in a liquid medium (Kratz \& Myers, 1955) containing $50 \mathrm{mM}-\mathrm{KNO}_{3}, 0.57 \mathrm{mM}-\mathrm{K}_{2} \mathrm{HPO}_{4}, 0.14 \mathrm{mM}-$ $\mathrm{MgSO}_{4}, 1.5 \times 10^{-5} \mathrm{M}-\mathrm{FeCl}_{3}$ and $1.5 \times 10^{-5} \mathrm{M}$-ammonium citrate. Flasks (1 litre) were illuminated with cool white light $(100 \mathrm{~W})$ at $25^{\circ} \mathrm{C}$.

Microscopic observations of phototaxis. Trichomes were inoculated in the centre of Petri dishes containing the above medium solidified with $2 \%(\mathrm{w} / \mathrm{v})$ agar (Nultsch, 1962). After the trichomes had swarmed out of the centre, sections of the agar $(4 \times 4 \mathrm{~mm})$ were cut out, placed on a microscope slide, and observed with a Reichert Univar photomicroscope using bright-field or interference-contrast optics. The initial light intensity was $10 \mathrm{~mW} \mathrm{~cm}^{-2}$, and neutral density filters were used to cause photophobic responses. The filters used were $\Delta \mathrm{J}_{1}(12 \%$ transmission), $\Delta \mathrm{J}_{2}(1.6 \%$ transmission $)$ and $\Delta \mathrm{J}_{3}(0 \cdot 19 \%$ transmission $)$. Reagents were dissolved in growth medium and added directly to the agar surface as drops $(10 \mu \mathrm{l})$.

Anaerobiosis. Anaerobic conditions were maintained by the glucose oxidase reaction. The reaction mixture, containing glucose $(50 \mathrm{~mm})$, glucose oxidase (EC 1.1.3.4;0.1 units $\mathrm{ml}^{-1}$ ) and catalase (EC 1.11.1.6;10 units $\mathrm{ml}^{-1}$ ), was added to the agar surface. The agar and trichomes were then sealed with a cover slip. The same reaction mixture without glucose oxidase served as a control.

Determination of the membrane potential. A $\mathrm{TPP}^{+}$-selective electrode was used for measurements of $\Delta \psi$ (Grinius et al., 1980). A 5-7 d old culture grown in liquid medium was disrupted in a blender (Häder \& Nultsch, 1973), centrifuged at $6000 \mathrm{~g}$ for $5 \mathrm{~min}$ and diluted with growth medium to a final concentration of 3 to $6 \mathrm{mg}$ (wet weight) $\mathrm{ml}^{-1}$. Blending served to separate and slice the trichomes, producing a homogeneous preparation in which the trichomes were fully phototactically active (Häder \& Nultsch, 1973). The electrode was inserted in a $2.5 \mathrm{ml}$ cuvette containing trichomes and $5 \times 10^{-6} \mathrm{M}-\mathrm{TPP}-\mathrm{Br}$. Changes in the membrane potential were calculated according to the following equation:

$$
\partial(\Delta \psi) / \partial(\Delta E)=\alpha \exp (\alpha F \Delta E / R T) /\{1-\exp (\alpha F \Delta E / R T)\}
$$

where $\Delta \psi$ is the membrane potential, $\Delta E$ is the difference between the electrode potentials before and after the addition of an uncoupler, $R$ is the gas constant, $F$ is the Faraday constant, $T$ is the absolute temperature and $\alpha$ is the coefficient describing deviation of the electrode calibration curve from the Nernst equation (Hosoi et al., 1980). The suspension was constantly stirred, and illuminated with a $200 \mathrm{~W}$ lamp.

Photoelectric measurements. The external electrode technique (Häder, 1978a) was used to measure the electrical potential difference between the two ends of trichomes. About 20 trichomes were placed in a gutter (1.5 $\times 0.1 \mathrm{~mm}$ ) made in a plexiglass plate. A silver electrode was placed in a compartment at each end of the cavity, and the system filled with distilled water. The signal from the electrodes passed through an electrometer (resistance, $10^{9} \Omega$ ) to an oscilloscope. The time resolution was $1 \mathrm{~ms}$. Trichomes were illuminated with a $100 \mathrm{~W}$ lamp (Glagolev et al., 1980).

Reagents. CCCP, FCCP, EGTA and catalase were from Sigma; glucose oxidase was from Serva and TPP-Br from Chemapol (Czechoslovakia). TTFB was a kind gift of Dr Jaguzhinski of this laboratory. Ionophore A23187 was from Calbiochem. All other chemicals used were of reagent grade.

\section{RESULTS}

\section{Sensing of $\Delta \bar{\mu}_{\mathrm{H}^{+}}$in the taxic response}

Trichomes reverse their direction of travel in response to a decrease in light intensity (photophobic response; Nultsch \& Häder, 1979). The action spectra of photosynthesis and 


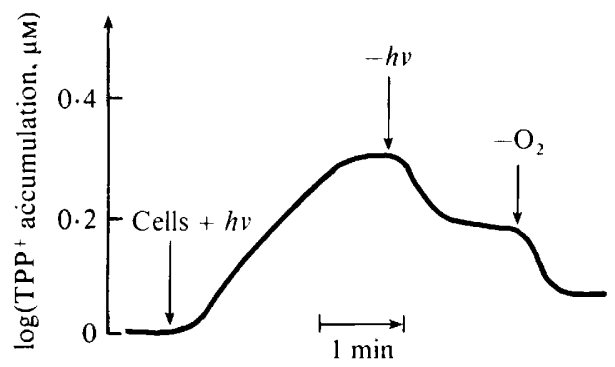

Fig. 1. Measurement of $\Delta \psi$ in $P$. uncinatum by $\mathrm{TPP}^{+}$transport. A $\mathrm{TPP}^{+}$electrode was placed in a $2.5 \mathrm{ml}$ vessel containing $5 \times 10^{-6} \mathrm{M}^{-\mathrm{TPP}^{+}}$and blended trichomes $\left(3.4 \mathrm{mg}\right.$ wet weight $\left.\mathrm{ml}^{-1}\right)$. Anaerobiosis was maintained by the glucose oxidase reaction. The ordinate shows the decrease of $\mathrm{TPP}^{+}$ in the outer medium. The addition of cells, the switching off of the light, and the addition of the glucose oxidase mixture (to remove oxygen), are indicated by arrows.

\section{Table 1. Effect of anaerobic conditions on the sensitivity of the photophobic response}

Observations were made with trichomes $72 \mathrm{~h}$ after they had swarmed out from the point of inoculation. Figures are the means of 30 measurements \pm S.D. Anaerobiosis was achieved by adding glucose, glucose oxidase and catalase to the surface of the agar and covering the trichomes with a cover slip.

\section{Measurement}

Mean time of reversing in response to the light decrease obtained with filter $\Delta \mathrm{J}_{2}$ (s) Mean minimal time necessary to evoke reversing in response to the large decrease in light intensity obtained with filter $\Delta \mathrm{J}_{3}(\mathrm{~s})$

Percentage of trichomes responding to the small decrease in light intensity obtained with filter $\Delta \mathbf{J}_{1}$

$\begin{array}{cc}\begin{array}{c}\text { Aerobic } \\ \text { conditions }\end{array} & \begin{array}{c}\text { Anaerobic } \\ \text { conditions }\end{array} \\ 54 \pm 3 & 31 \pm 2 \\ 24 \pm 2 & 9 \pm 1\end{array}$

0

30

the photophobic response closely coincide (Nultsch, 1962), suggesting that $\Delta \bar{\mu}_{\mathrm{H}^{+}}$is the parameter that is being registered in phototaxis. Alternatively, the light pigments could serve as specific receptors, or the level of reduction of an acceptor in the electron transport chain could govern phototaxis (the 'electron pool hypothesis'; Häder, 1974, 1975). To distinguish between these possibilities, we attempted to produce different changes in $\Delta \bar{\mu}_{\mathrm{H}^{+}}$in response to a given light decrease. If $\Delta \bar{\mu}_{\mathrm{H}^{+}}$can be generated in the same membrane by both photosynthesis and respiration, a small decrease in light intensity would produce an insufficient decrease in $\Delta \bar{\mu}_{\mathrm{H}^{+}}$under aerobic conditions and a pronounced decrease in $\Delta \bar{\mu}_{\mathrm{H}^{+}}$under anaerobic conditions when light is the only means of supporting $\Delta \bar{\mu}_{\mathrm{H}^{+}}$.

Measurements of $\mathrm{TPP}^{+}$accumulation by a suspension of $P$. uncinatum trichomes (Fig. 1) demonstrated that both light-linked and respiratory-linked redox chains could energize the cytoplasmic membrane. The sensitivity of the photophobic response to insertion of a neutral density filter $\left(\Delta \mathrm{J}_{2}\right)$ markedly increased under anaerobic conditions (Table 1). When a large decrease in light intensity was achieved with filter $\Delta \mathrm{J}_{3}$, the sensitivity of the response was again greater under anaerobic conditions (Table 1). Finally, a threshold light decrease that had no effect on aerobic trichomes effectively repelled $P$. uncinatum under anaerobiosis (Table 1). The simplest explanation of the experiment is that $P$. uncinatum senses changes in $\Delta \bar{\mu}_{\mathrm{H}^{+}}$, but not in light per se. The response of $P$. uncinatum to changes in $\Delta \bar{\mu}_{\mathrm{H}^{+}}$other than that caused by varying the light intensity was determined. When added to gliding trichomes, the uncouplers CCCP and FCCP caused reversals, thus acting as effective repellents. The ability of these uncouplers to decrease the light-induced $\Delta \psi$ (assuming that $\mathrm{TPP}^{+}$is accumulated in accordance with the Nernst equation (Grinius et al., 1980) was quantitatively correlated with their repelling action (Fig. 2). Increasing concentrations of $\mathrm{CCCP}$ were equally effective in decreasing $\Delta \psi$ and in eliciting a phobic response. 


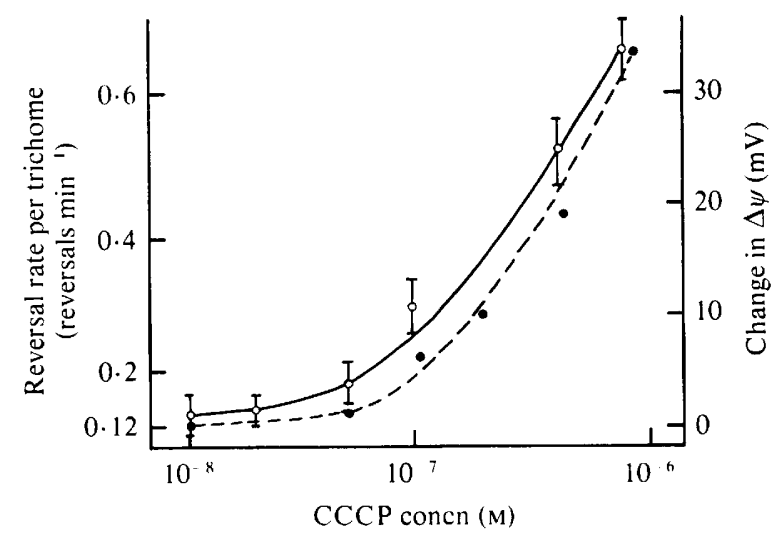

Fig. 2. Repelling and uncoupling action of CCCP on P. uncinatum. The membrane potential was determined as in Fig. 1. Change in $\Delta \psi(O)$ is the difference between $\Delta \psi$ without and with the given concentration of CCCP. The reversion rate $(O)$ was determined immediately after the addition of CCCP. Each point represents the mean of 20 individual measurements. The bars represent standard deviations.

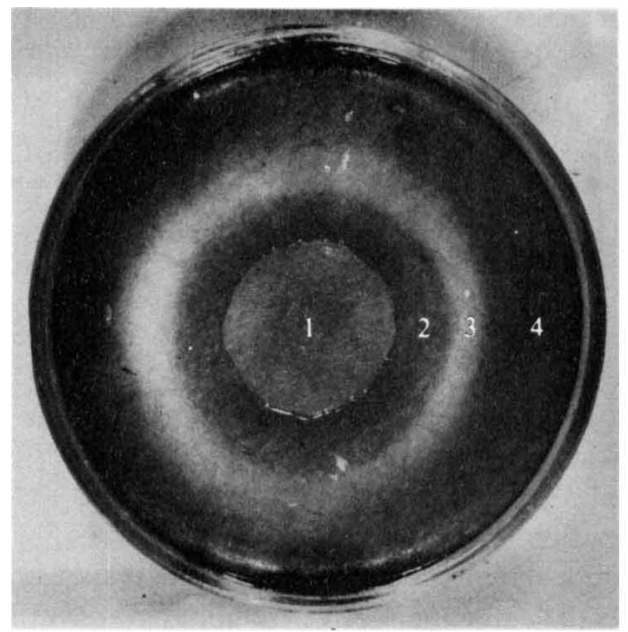

Fig. 3

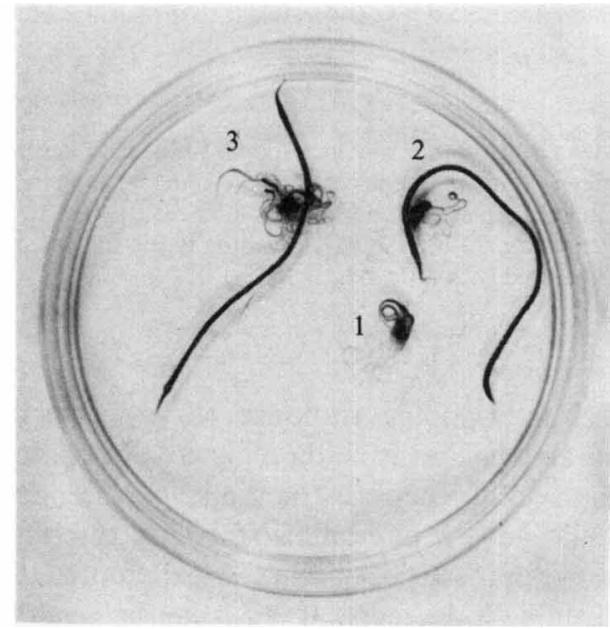

Fig. 4

Fig. 3. Negative chemotaxis of $P$. uncinatum from an uncoupler. A tissue paper disc was soaked with 8 $\times 10^{-3} \mathrm{M}$-TTFB and applied to the centre of a plate with uniformly spread trichomes. The photograph was taken $8 \mathrm{~h}$ later; it shows: 1, the tissue paper; 2 , trichomes immobilized by a high concentration of the uncoupler; 3 , a light zone formed after the trichomes had swarmed out of it; 4, a band of trichomes that have accumulated at the periphery of the dish.

Fig. 4. Negative chemotaxis of $P$. uncinatum from an old culture exudate. A thread was soaked in water that had been flooded on to the surface of an old culture, and was placed on a dish with young swarming trichomes. 1, Trichomes swarming out of an inoculation point; 2 , trichomes repelled by a thread soaked in an exudate from an old culture; 3 , trichomes gliding over a thread soaked in the growth medium.

Uncouplers were also tested for their ability to repel cyanobacteria in a spatial gradient assay (Tso \& Adler, 1974). Homogenized trichomes were suspended in $0.3 \%(\mathrm{w} / \mathrm{v})$ agar in a Petri dish, and a disc of tissue paper, soaked in $8 \mathrm{mM}$-TTFB solution, was applied to the surface of the dish (Fig. 3). Trichomes near the edge of the disc were immediately immobilized, while the rest glided down the uncoupler gradient, leaving an empty zone in their wake.

High concentrations of uncouplers and the permeant cation $\mathrm{TPMP}^{+}$have been reported to 
inhibit photophobic responses in $P$. uncinatum (Häder, 1979). We confirmed this result, and also observed inhibition of the photophobic response by CCCP, $\mathrm{TPP}^{+}$and valinomycin. Both light-induced and spontaneous reversals became suppressed (results not shown). Inhibition of taxis in this case may be due to the arrest of $\Delta \bar{\mu}_{\mathrm{H}^{+}}$-dependent fibrillar reversion at low levels of $\Delta \bar{\mu}_{\mathrm{H}^{+}}$. A similar situation appears to exist in Bacillus subtilis and Escherichia coli (Khan \& Macnab, 1980).

Apart from the simple inhibitory effect of uncouplers and ionophores on taxic responses, we observed an unusual negative photophobic response in the presence of $10^{-4} \mathrm{M}$ - $\mathrm{TPP}^{+}$or $10^{-5} \mathrm{M}$-valinomycin. After a decrease in light intensity (which had no effect), increasing light caused a reversal within $30 \mathrm{~s}$ (results not shown). It seems probable that the negative taxis signal generated following a light decrease was ineffective, due to an arrest of the reversal mechanism. However, an increase in illumination caused an increase in $\Delta \bar{\mu}_{\mathrm{H}^{+}}$, triggering the preformed signal. After 5-10 min illumination at a given light intensity (in the presence of $10^{-4} \mathrm{M}-\mathrm{TPP}^{+}$), the trichomes failed to respond to a light increase.

\section{The sequence of information processing steps}

By interfering with the taxis system at different levels, it is possible to determine the sequence of steps involved in information processing. If we consider $\Delta \bar{\mu}_{\mathrm{H}^{+}}$sensing to take part at the reception step, it would be reasonable to assume that the information next reaches the methyl-accepting chemotaxis proteins (MCPs) that were found to collect information from individual receptors in E. coli (Springer et al., 1977; Silverman \& Simon, 1977). Sensory transduction may be interrupted at the level of MCP methylation by introducing an analogue of methionine, L-ethionine (Schimz \& Hildebrand, 1979). Incubation with ethionine ( $2 \mathrm{mM})$ for $30 \mathrm{~min}$ inhibited the photophobic response in $P$. uncinatum twofold (results not shown), suggesting that one or more MCPs take part in transducing information gained from $\Delta \bar{\mu}_{\mathrm{H}^{*}}$ reception. In a control experiment, methionine $(2 \mathrm{mM})$ had no effect.

The addition of $\mathrm{Ca}^{2+}$ and the $\mathrm{Ca}^{2+}$ ionophore $\mathrm{A} 23187$ (each at $10^{-5} \mathrm{M}$ ) to trichomes pretreated with ethionine caused oscillatory reversals of trichomes, indicating that $\mathrm{Ca}^{2+}$ regulates reversals at a stage that follows the methylating processes. The addition of a high concentration of CCCP $\left(2 \times 10^{-6} \mathrm{M}\right)$ to trichomes oscillating in the presence of $\mathrm{Ca}^{2+}$ and A23187 totally suppressed reversals. This observation supports the conclusion of Khan \& Macnab (1980) that under conditions of lowered $\Delta \bar{\mu}_{\mathrm{H}^{+}}$the sequence of information processing steps is interrupted at the level of the flagellar rotary motor.

\section{Synchronization of cells within a trichome}

We noticed that in a viscous environment, the rate of spontaneous reversals increased. The reversals became oscillatory (once every $15-20 \mathrm{~s}$ ) if $4 \%(\mathrm{w} / \mathrm{v})$ solutions of polyvinylpyrollidone (mol. wt 350000 ) or Ficoll (mol. wt 400000 ), or $1 \%(\mathrm{w} / \mathrm{v})$ agar (at $30^{\circ} \mathrm{C}$ ) were added to trichomes on the surface of $2 \%(\mathrm{w} / \mathrm{v})$ agar plates. The rate of movement decreased several fold. Under such conditions, a decrease in light intensity (obtained by using the neutral density filter $\Delta \mathrm{J}_{2}$ ) increased the motility rate three- to fivefold for about $20 \mathrm{~s}$. Some trichomes came to a standstill in a viscous solution; a light stimulus then initiated gliding for about $30 \mathrm{~s}$. If the end of an immotile trichome ( $15 \%$ of its length) was illuminated by a light spot and the light intensity was then decreased, the trichome began to glide for about $30 \mathrm{~s}$. In response to a viscous environment, individual cells may periodically initiate negative taxis signals, causing the asynchronization of movement in different parts of the trichome. A strong uniformlyspreading stimulus (change in $\Delta \bar{\mu}_{\mathbf{H}^{+}}$) would temporarily synchronize all the cells and allow the trichome to move.

It is possible to follow the direction of motion of individual cells by suspending trichomes in a liquid medium and staining the slime with India ink (Walsby, 1968). In the absence of a 


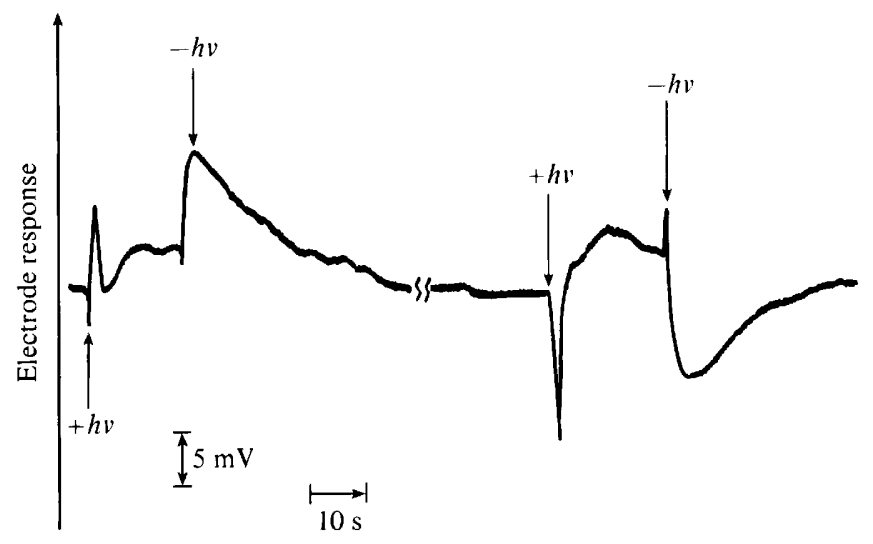

Fig. 5. Electrical responses of $P$. uncinatum trichomes. About 20 trichomes were placed between two silver electrodes and after a synchronizing procedure the light was turned on and off as indicated by the arrows. Trichomes were synchronized by illuminating one end of the batch (approx. two-thirds of its length) with a bright spot of light and then switching off the light (see text). The time between the two light-dark cycles shown in the figure was $90 \mathrm{~s}$.

solid contact, the slime forms rings that move throughout the trichome. When suspended in a $4 \%(\mathrm{w} / \mathrm{v})$ aqueous solution of Ficoll with India ink, rings of slime on the surface of the trichomes oscillated with an amplitude of 3 to $30 \mu \mathrm{m}$, rather than moving uniformly to one end, thus showing a degree of asynchronization.

An aqueous extract from a Petri dish containing a 10-d-old culture of $P$. uncinatum was obtained by spreading $0.5 \mathrm{ml}$ distilled water on the surface of the agar and collecting it $2 \mathrm{~min}$ later. A thread soaked in this extract repelled trichomes in a spatial assay (Fig. 4). When added to trichomes, the extract increased the rate of spontaneous reversals fivefold and brought many trichomes to a standstill. A local or total light decrease temporarily initiated gliding in the immotile trichomes. The addition of $5 \times 10^{-7} \mathrm{M}$-CCCP restored motility in all of the trichomes. The uncoupler may have activated motility by arresting reversals, thus synchronizing all the cells. The addition of $1 \mathrm{~mm}$-EGTA also restored motility in immotile trichomes (results not shown) presumably due to its inhibiting reversals by binding $\mathrm{Ca}^{2+}$ (Murvanidze \& Glagolev, 1981).

It seems that if repellent stimuli spread uniformly among the cells, as in the case of $\Delta \bar{\mu}_{\mathrm{H}^{+}}$ perturbations caused by changes in light or uncoupler concentrations, cells react synchronously. If an intense repellent stimulus is not of uniform nature, as in the case of viscosity or chemorepellents, different cells initiate a taxis signal randomly, causing asynchronous reversals and the immobilization of the trichome.

\section{The taxic signal}

If a batch of 20-30 trichomes is illuminated with uniform light, external electrodes register an irregular signal of unpredictable sign between the ends of the trichomes. The same applies when the light is turned off. Since it is known that the anterior part of the trichome (approx. $15 \%$ of the total length) is more sensitive to light stimulus than the rest of the trichome (Drews, 1959), we attempted to synchronize all the trichomes in the batch. A large spot of light was trained on one end of the batch (approx. two-thirds of the trichomes' length) and turned off $1 \mathrm{~min}$ later. Those trichomes moving towards the light must have reversed, while those moving away from the spot must not have, due to the insensitivity of the 'tail' end. This procedure was expected to orient all of the trichomes with their 'heads' in the same direction. Then a uniform light was switched on and off (Fig. 5); a large-amplitude signal followed. A second cycle of light-dark stimulus produced a mirror-image of the first response. The 
sequential light-dark cycles brought the batch to the initial (asynchronous) state, probably because the trichomes became asynchronized during spontaneous reversals in the period between the light stimuli. However, it was possible to obtain the two sequential opposing signals after a new synchronization.

\section{DIS C US SION}

Cyanobacteria lack specific receptors for photophobic response, and the coincidence of action spectra for photosynthesis and for accumulation in a light spot (Nultsch, 1962) may be most readily explained by the organisms' ability to sense $\Delta \bar{\mu}_{\mathrm{H}^{+}}$. In the present study, we found that the sensitivity of the photoresponse depended not on the change of light intensity, but on its ability to produce changes in $\Delta \bar{\mu}_{\mathrm{H}^{+}}$. Moreover, uncouplers appeared to be potent repellents, in both spatial gradient and temporal gradient assays. The repelling action of uncouplers first described by Clayton (1958) and extensively studied by Ordal \& Goldman $(1975,1976)$ in Bacillus subtilis is at present a subject of controversy. Repulsion by uncouplers is considered to result from $\Delta \bar{\mu}_{\mathrm{H}^{+}}$sensing (Miller \& Koshland, 1977; Glagolev, 1978, 1980) or specific chemoreception (Ordal \& Villani, 1980). Using the fluorescent probe for $\Delta \psi, 3,3^{\prime}$ dipropylthiodicarbocyanine iodide, no correlation between the uncoupling ability and repelling activity of pentachlorophenol was found for B. subtilis (Ordal \& Villani, 1980). In contrast, when we monitored $\Delta \psi$ by TPP ${ }^{+}$accumulation in $P$. uncinatum, a good correlation between the uncoupling and repelling efficiencies of CCCP was found (Fig. 2).

The problem of synchronizing individual cells of a trichome, absent in the case of $\Delta \bar{\mu}_{\mathrm{H}^{+}}$ sensing, becomes apparent when other chemoeffectors are used. A viscous environment or an aqueous extract from a 12-d-old culture cause cells to oscillate asynchronously. The addition of EGTA arrests reversals, suggesting that individual cells may initiate a taxis signal, leading to $\mathrm{Ca}^{2+}$ accumulation. Although $\mathrm{Ca}^{2+}$ has been found to regulate reversals in B. subtilis (Ordal, 1977), there seemed to be no influx of $\mathrm{Ca}^{2+}$ into the cells following a repellent stimulus (Ordal \& Villani, 1980) and it was therefore suggested that $\mathrm{Ca}^{2+}$ switched between a bound and a free form within the cytoplasm. It seems possible that $\mathrm{Ca}^{2+}$ may not reequilibrate rapidly between the cytoplasm and the outer medium, but rather becomes sequestrated outside the cytoplasmic membrane in the periplasm or the cell wall.

$\mathrm{Ca}^{2+}$ cannot play the sole role of a chemotactic signal, since trichomes rapidly reverse in the presence of $\mathrm{A} 23187$ and high $\mathrm{Ca}^{2+}$ concentrations, i.e. at a presumably constant intracellular $\mathrm{Ca}^{2+}$ concentration. The taxis signal may, therefore, be a $\mathrm{Ca}^{2+}$-depolarizing wave, increasing $\mathrm{Ca}^{2+}$ concentration in the cytoplasm. A decreased $\Delta \psi$ would allow $\mathrm{Ca}^{2+}$ to bind to the motor and change the direction of rotation (Murvanidze \& Glagolev, 1981).

An electrical signal following a light increase or decrease in $P$. uncinatum was reported by Häder $(1978 a, b)$. In contrast, we were unable to obtain reproducible signals following changes of light in a batch of trichomes. Perhaps the discrepancy is due to a strain difference. However, after alignment of the sensitive anterior parts of the trichomes, singly polarized electrical signals were registered following two sequential dark periods. This depolarization may represent the electrical taxic signal which might be expected to change its polarity, as trichomes change the position of the sensitive end after each reversal.

Thanks are due to Drs L. M. Chaylakhan, T. V. Potapova and S. Levin for helpful discussion, and aid in the external electrode technique; we are grateful to Dr L. Grinius for a kind gift of the $\mathrm{TPP}^{+}$electrode and to Calbiochem for a generous gift of A23187. Stimulating discussions with Professor V. P. Skulachev and Dr M. Yu. Sherman are gratefully acknowledged. 


\section{REFERENCES}

Clayton, R. K. (1958). On the interplay of environmental factors affecting taxis and motility in Rhodospirillum rubrum. Archiv für Mikrobiologie 29, 189-212.

Drews, G. (1959). Beiträge zur Kenntnis der phototaktischen Reaktionen der Cyanophyceen. Archiv für Protistenkunde 104, 389-430.

Glagolev, A. N. (1978). The proton motive force in bacterial motility and taxis. Proceedings, 12 th FEBS Meeting, Abstract no. 1867.

Glagolev, A. N. (1980). Reception of the energy level in bacterial taxis. Journal of Theoretical Biology 82 $171-185$.

Glagolev, A. N., Glagoleva, T. N., Levin, S. A., Potapova, T. V., Skulachev, V. P. \& Chailachian, L. M. (1980). Transport of energy along the cyanobacterial trichome in the form of a membrane potential. Dokladi Akademii nauk SSSR 255, 1490-1493.

Glagoleva, T. N., Glagolev, A. N., Gusev, M. V. \& Nikitina, K. A. (1980). Protonmotive force supports gliding in cyanobacteria. FEBS Letters $117,49-53$.

Grinius, L. L., Dangelavicius, R. J. \& Alkimavicius, G. A. (1980). Study of the membrane potential of the Bacillus subtilis and Escherichia coli cells by the penetration ions method. Biokhimia 45, 1609-1618.

HÄDER, D.-P. (1974). Participation of two photosystems in the photophobotaxis of Phormidium uncinatum. Archives of Microbiology 96, 255-266.

HÄDER, D.-P. (1975). The effect of inhibitors on the electron flow triggering photophobic reactions in Cyanophyceae. Archives of Microbiology 103, 169174.

HÄDER, D.-P. (1977). Influence of electrical fields on photophobic reactions in blue-green algae. Archives of Microbiology 114, 83-86.

HÄDER, D.-P. (1978a). Evidence of electrical potential changes in photophobically reacting blue-green algae. Archives of Microbiology, 118, 115-119.

HÄDER, D.-P. (1978b). Extracellular and intracellular determination of light-induced potential changes during photophobic reactions in blue-green algae. Archives of Microbiology 119, 75-79.

HÄDER, D.-P. (1979). Effect of inhibitors and uncouplers on light-induced potential changes triggering photophobic responses. Archives of Microbiology 120, 57-63.

HÄDER, D.-P. \& Nultsch, W. (1973). Negative photo-phobotactic reactions in Phormidium uncinatum. Photochemistry and Photobiology 18. 311-317.

Halfen, L. N. \& Castenholz, R. W. (1971). Gliding motility in the blue-green algae Oscillatoria princeps. Journal of Phycology 7, 133-145.

Hosol, S., Mochizuki, N., Hayashi, S. \& Kasal, M. (1980). Control of membrane potential by external $\mathrm{H}^{+}$concentration in Bacillus subtilis as determined by an ion-selective electrode. Biochimica et biophysica acta 600, 844-852.
Khan, S. \& Macnab, R. M. (1980). The steady-state counter-clockwise/clockwise ratio of bacterial flagellar motors is regulated by proton motive force. Journal of Molecular Biology 138, 563-597.

Kratz, W. A. \& Myers, J. (1955). Nutrition and growth of several blue-green algae. American Journal of Botany 42, 282-287.

Larsen, S. H., Reader, R. W., Kort, E. N., Tso, W.-W. \& ADLER, J. (1974). Change in direction of flagellar rotation is the basis of chemotactic response in Escherichia coli. Nature, London 249, 74-77.

Miller, J. B. \& Koshland, D. E., JR (1977). Sensory electrophysiology of bacteria: relationship of the membrane potential to motility and chemotaxis in Bacillus subtilis. Proceedings of the National Academy of Sciences of the United States of America 74, 4752-4756.

Murvanidze, G. V. \& Glagolev, A. N. (1981). Ca ${ }^{2+}$ ions regulate reversions in phototactically active Phormidium uncinatum and Halobacterium halobium. FEMS Microbiology Letters 12, 3-6.

NultsCH, W. (1962). Der Einfluss des Lichtes auf die Bewegung der Cyanophyceen. III. Photophobotaxis von Phormidium uncinatum. Planta 58, 647-663.

Nultsch, W. \& HÄDER, D.-P. (1979). Photomovement of motile micro-organisms. Photochemistry and Photobiology 29, 423-437.

Ordal, G. W. (1977). Calcium ion regulates chemotactic behaviour in bacteria. Nature, London $\mathbf{2 7 0}$, $66-67$.

Ordal, G. W. \& Goldman, D. J. (1975). Chemotaxis away from uncouplers of oxidative phosphorylation in Bacillus subtilis. Science 189, 802-805.

Ordal, G. W. \& Goldman, D. J. (1976). Chemotactic repellents of Bacillus subtilis. Journal of Molecular Biology 100, 103-108.

Ordal, G. W. \& Villani, D. P. (1980). Action of uncouplers of oxidative phosphorylation as chemotactic repellents of Bacillus subtilis. Journal of General Microbiology 118, 471-478.

Schimz, A. \& Hildebrand, E. (1979). Chemosensory responses of Halobacterium halobium. Journal of Bacteriology 140, 749-753.

Silverman, M. \& Simon, M. (1977). Chemotaxis in Escherichia coli: methylation of the gene products. Proceedings of the National Academy of Sciences of the United States of America 74, 3317-3321.

Springer, M. S., Goy, M. F. \& Adler, J. (1977). Sensory transduction in Escherichia coli: two complementary pathways of information processing that involve methylated proteins. Proceedings of the National Academy of Sciences of the United States of America 74, 3312-3316.

Tso, W.-W. \& ADlER, J. (1974). Negative chemotaxis in Escherichia coli. Journal of Bacteriology 119 , 640-642.

WALSBY, A. E. (1968). Mucilage secretion and the movement of blue-green algae. Protoplasma 65, 223-238. 